\title{
ÇCKNT Katkılı ve Katkısız CETP Kompozitlerin Zımba İle Delinmesinde Zımba Profilinin Elde Edilen Pullara Etkisi
}

\author{
${ }^{* 1}$ Ferhat Ceritbinmez \\ ${ }^{* 1}$ Haier Europe - Candy Hoover Group, Eskişehir, Türkiye
}

\section{Özet :}

İmalat sektörlerinde pul ihtiyacı genellikle zımba ve kalıp sistemleri kullanılarak karşılanmaktadır. Bu sistemlerde istenilen pul çapı kalıp mühre çapına işlenmekte, zımba çapı ise kesme boşluğu ölçüsü kadar küçültülerek delme işlemleri kalıp veya aparatlar üzerinde yapılmaktadır. Bu çalışmada ÇCKNT (çok cidarlı karbon nanotüp) katkılı ve katkısız CETP (cam elyaf takviyeli polimer) kompozit malzemelere $0.16 \mathrm{~mm}$ kesme boşluğu bulunan kalıplarda $90^{\circ}, 15^{\circ}, 30^{\circ}, \mathrm{V}, \mathrm{C}$ tipi kesme formu bulunan $\varnothing 8 \mathrm{~mm}$ 'lik zımbalar ile delik delinerek elde edilen pullar incelenmiştir. Yapılan çalışma neticesinde elde edilen pulların zımba kesme formunu aldığı, katkısız kompozitlerin $90^{\circ}$ düz formlu zımba ile delinmesinde elde edilen pul çapının zımba ve mühre çapına göre sırasıyla $\% 4.75$ ve $\% 0.72$ oranında daha büyük ölçüde olduğu tespit edilmiştir. Ayrıca CETP kompozit malzemelere ÇCKNT katkısı malzemelerin dayanımını arttırarak zımba ile kesilmesi neticesinde elde edilen pulların daha rijit olmasını sağlamıştır. Bu sebeple katkılı kompozitlerin pul çapının zımba çapından büyük, mühre çapından küçük olduğu tespit edilmiştir.

Anahtar kelimeler : CETP, ÇCKNT, Pul, Zımba profili

\section{The Effect of Punch Profile on the Slugs Obtained in Punching of MWCNTs doped and undoped GFRP Composites}

\begin{abstract}
:
The need for stamps in manufacturing sectors is generally met by using punch and die systems. In these systems, the desired slug diameter is processed into the die diameter, the punch diameter is reduced by the amount of the cutting gap size and the punching operations are performed on the molds or apparatus. In this study, the slugs obtained by punching holes in MWCNTs (multi walled carbon nanotubes) doped and undoped GFRP (glass fiber reinforced polymer) materials using Ø8 $\mathrm{mm}$ punches with $90^{\circ}, 15^{\circ}, 30^{\circ}, \mathrm{V}, \mathrm{C}$ type cutting forms in molds with $0.16 \mathrm{~mm}$ cutting gap were examined. As a result of the study, it was determined that the slugs obtained in the punch cutting form took the form of punch cutting, and the diameter of the slugs obtained in the punching of the undoped composites with a $90^{\circ}$ flat form punch was $\% 4.75$ and $\% 0.72$ larger than the punch and die diameters, respectively. In addition, MWCNTs additive to GFRP composite materials increased the strength of the materials and ensured that the slugs obtained as a result of cutting the material with a punch were more rigid. For this reason, it was determined that the slug diameter of the doped composites was larger than the punch diameter and smaller than the mold diameter.
\end{abstract}

Key words: GFRP, MWCNTs, Slug, Punch Profile

*Corresponding author: Address: Haier Europe - Candy Hoover Group, Organize Sanayi Bölgesi 8.Cd. No:1 26110, Eskişehir, TURKEY. E-mail address: ferhatceritbinmez@gmail.com, Phone: +90222360650 


\section{Giriş}

Levha veya şerit haldeki metal, kompozit, plastik vb. malzemeleri kendilerinden daha sert kesmedelme zımbaları ve dişi kalıplar kullanarak; malzemeleri ayırma işlemi, kalıpçılıkta zımba ve kalıp yöntemiyle kesme ve delme olarak tanımlanmaktadır. Kesme - delme olayı zımbanın malzemenin üzerine baskı yapması ile başlar ve parçanın tamamen tabakadan ayrılması ile sonra erer. Bu süreçte elastik bölge deformasyonu, plastik deformasyon, pekleşmenin azalış1, kesme kenarları arası çatlak başlaması ve ilerlemesi, en son ise parça çıkışı safhaları gerçekleşir. Kalıp kullanarak kesme - delme işleminde kullanılan malzemenin cinsine, kalınlığına göre dişi ve erkek arasına çalışma boşluğu verilmektedir. Söz konusu kesme boşluğu kesilen parçanın yüzey kalitesine, kalıbın ve zımbanın ömrüne, kesme - delme için gerekli olan kuvvete ciddi şekilde etki etmektedir [1]. Kesme boşluğunun kalıp tarafına verilerek pul elde edilmesini tarif eden bir kesme operasyonu Şekil 1'de gösterilmiştir.

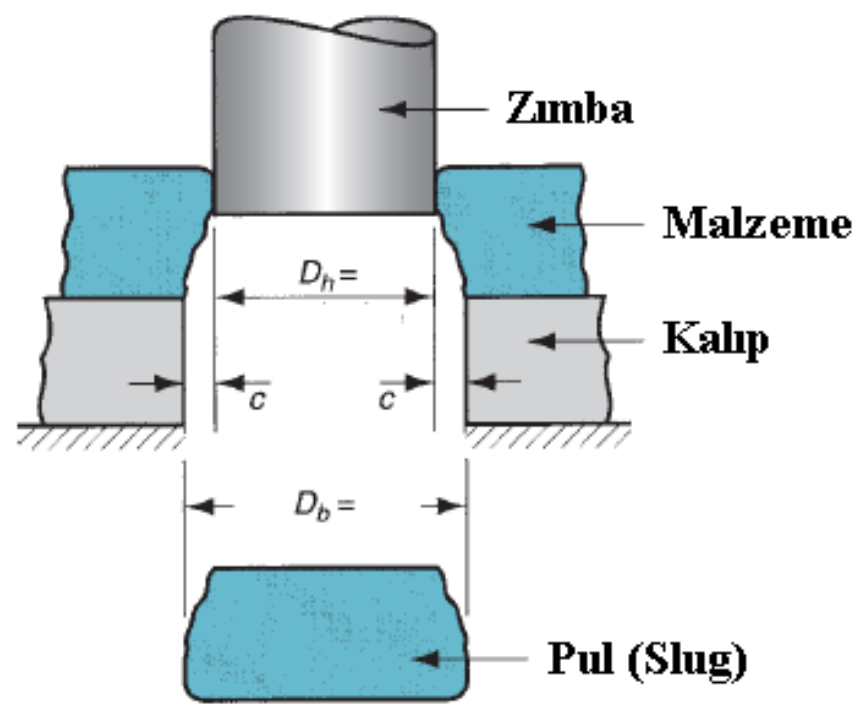

Şekil 1. Zımba ile delik delme - pul elde etme [2]

Literatürde metal malzemelerin zımba ve kalıp kullanılarak delinmesi üzerine bir çok çalışma bulunmaktadır. Fakat kompozit malzemelerin bu yöntemle delinmesi ve bu deliklerden çıkan pulların analizi üzerine çalışma pek bulunmamaktadır. Ceritbinmez ve Yapıcı, ÇCKNT (çok cidarlı karbon nanotüp) katkılı ve katkısız CETP (cam elyaf takviyeli polimer) kompozitlerin farklı kesme profilli zımbalar ile delinmesinde, zımba kesme formunun kesme kuvvetine etkisini yük hücreleri ve fujifilm basınç ölçüm yöntemleri ile analiz etmiştir. Ayrıca kesme boşluğunun kesim kalitesine ve kesme kuvvetine etkilerini belirlemeye çalışmışlardır [3]. Patnaik ve arkadaşları, saç metal kalıplarında zımba ile kesilen pulların zımbaya yapışıp çıkması yani kalıp çeliğinden akmama problemi üzerine çalışmalar yapmıştır. Bu problemin giderilmesi için zımba ve kalıp modifikasyonları önermiş̧lerdir. İticili zımba, hava kanallı zımba, çentikli zımba, kademeli sabit pimli zımba, yarı küresel uçlu zımba, kademeli kesme formlu zımba, kesme açısına sahip zımba kullanımının yanı sıra vakumlu, oluklu, yivli, eliptik, ters açılı ve hava kanallı kalıp kullanımının bu probleme çözüm olabileceğini vurgulamışlardır [4]. Küçüktürk, 
AA5754 Alüminyum sac malzemesini yedi farklı kesme boşluğu bulunan kalıplarda delerek kesme kuvvetlerini yük hücreleri yardımı ile ölçmüştür. Ayrıca kesilen parçaları optik mikroskopla inceleyerek ortalama çapak yükseklikleri ve kesme düzlüğü boyu / kopma boyu oranlarını belirlemiştir. Kesme boşluğu değerinin artmasının zımba batma yüksekliğini arttırdığını, kesme kuvveti ihtiyacını ve kesme düzlüğü boyunun ise azalmasına sebep olduğunu bildirmiştir [5]. Hsu ve arkadaşları, sac metal kalıpların delinmesi neticesinde ortaya çıkan pul'un dişi çelik içerisinden akmayıp zımba ile tekrar kalıp içerisine çıkması problemine; malzemenin çekme dayanımı, zımba/kalıp boşluğu, zımba pah açısı ve zımba köşe radüsü'nün etkisini incelemişlerdir. Bu probleme zımba köşe radüsünün etkisinin olmadığını rapor etmişlerdir [6]. Kompozit malzemeler yüksek mukavemet-ağırlık oranı, yüksek spesifik modül, kırılma tokluğu ve korozyon direnci gibi üstün özelliklerinden dolayı başta havacılık ve otomotiv sektörleri olmak üzere bir çok endüstriyel uygulamalarda yaygın olarak kullanılmaktadır [7-11]. Bu malzemelerin işlenebilirliklerini detaylıca araştırmak kullanım yerlerine montajı veya farklı kullanım alanlarının elde edilmesi açısından önem taşımaktadır. Bu sebeplerden dolayı, literatürden farklı olarak bu çalışmada kompozit malzemelerin zımba ve kalıp kullanılarak delinmesi neticesinde elde edilen pullar incelenmiştir.

\section{Materyal ve yöntem}

\subsection{CETP ve \% 0.1 ÇCKNT katkılı kompozit test malzemeleri}

Bu çalışmada pul elde etmek için ÇCKNT katkılı ve katkısız CETP malzemeler zımba ve kalıp kullanılarak delinmiştir. Seçilen bu malzemeler 8 tabaka cam elyafi, epoksi reçine gibi fiber ve matrislerin vakum infüzyon yönteminde birleştirilmesi ile elde edilmiştir. ÇCKNT katkılı kompozit imalatında nano partikül katkı oranı reçine miktarının \% 0.1'i oranındadır. CETP ve ÇCKNT katkı1ı kompozit test numune kalınlıkları sırası ile $1.70 \pm 0.1 \mathrm{~mm}$ ve $1.50 \pm 0.1 \mathrm{~mm}$ olarak ölçülmüştür ayrıca bu malzemelerin mekanik özellikleri Tablo 1'de gösterilmiştir.

Tablo 1. Katkılı ve katkısız kompozit malzemelerin mekanik özellikleri

\begin{tabular}{cccccc}
\hline $\begin{array}{c}\text { Malzeme } \\
(\boldsymbol{\%} \mathbf{0 . 1} \text { ÇCKNT) }\end{array}$ & $\begin{array}{c}\text { Yoğunluk } \\
\left(\mathbf{g} / \mathbf{c m}^{3}\right)\end{array}$ & $\begin{array}{c}\text { Elastisite } \\
\text { Modülü } \\
(\mathbf{G P a})\end{array}$ & $\begin{array}{c}\text { Maksimum } \\
\text { Kuvvet } \\
(\mathbf{k N})\end{array}$ & $\begin{array}{c}\text { Maks.Çekme } \\
\text { Gerilmesi } \\
(\mathbf{M p a})\end{array}$ & $\begin{array}{c}\text { Kopma } \\
\text { Uzama } \\
(\boldsymbol{\%})\end{array}$ \\
\hline CETP & 1.62 & 22.97 & 13.74 & 338.811 & 2.16 \\
ÇCKNT + CETP & 1.59 & 24.99 & 14.53 & 364.303 & 1.29 \\
\hline
\end{tabular}

\subsection{Zımba ve kalıp malzemeleri}

Üretimi tamamlanan kompozit malzemeler zımba ve kalıp yöntemi kullanılarak delinmiştir. Delme işlemi için $90^{\circ}, 15^{\circ}, 30^{\circ}, \mathrm{V}, \mathrm{C}$ tipi kesme formu bulunan $\varnothing 8 \mathrm{~mm}$ 'lik zımbalar, charmilles robofil 290P tel erozyon (WEDM) tezgahında hazırlanmıştır. Endüstride yaygın olarak kullanılan; mukavemet gerektiren yerlerde tercih edilen $90^{\circ}$ tipi, daha az kuvvet ile kesme sağlayan $15^{\circ}$ ve $30^{\circ}$ tipi, makaslamanın yapıldığ $\mathrm{V}$ tipi ve delgeçlerde tercih edilen için $\mathrm{C}$ tipi zımba modellleri seçilmiştir (Şekil 2). Tel erozyon tezgahında kesme formları işlenen zımbalar Güvenal Kalıp Elemanları A.Ş. firmasından tedarik edilmiştir. 


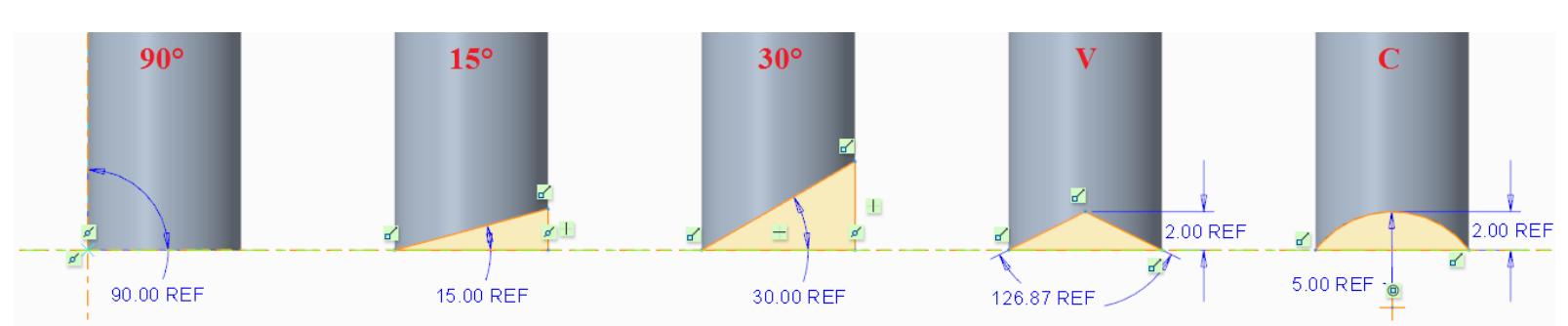

Şekil 2. Kullanılan zımbaların kesme profilleri [3]

Tüm laminatlar atölye tipi manuel hidrolik pres yardımı ile delinmiştir. Hazırlanan kesme kalıbı hidrolik presin çalışma masasına yerleştirilmiş ve daha sonra zımba kafasına pres pistonu ile kuvvet uygulanmıştır. Tüm parçalar merkezleme pimleri yardımı ile dikey olarak hizalanmıştır. Kompozit tabakaların delinmesi neticesinde her baskıda elde edilen pul (hurda) dişi kalıp içerisinden çıkarılmış, elyaf ve epoksi tozları temizlenerek bir sonraki baskı işlemi yapılmıştır. Her bir kesme boşluğu ve zımba profili için saf ve katkılı kompozit tabakalara üç ayrı delme işlemi yapılmıştır. Ölçüsel değerlerin tespit edilmesinde zımbalanan pulların ortalama değerleri rapor edilmiştir (Şekil 3).

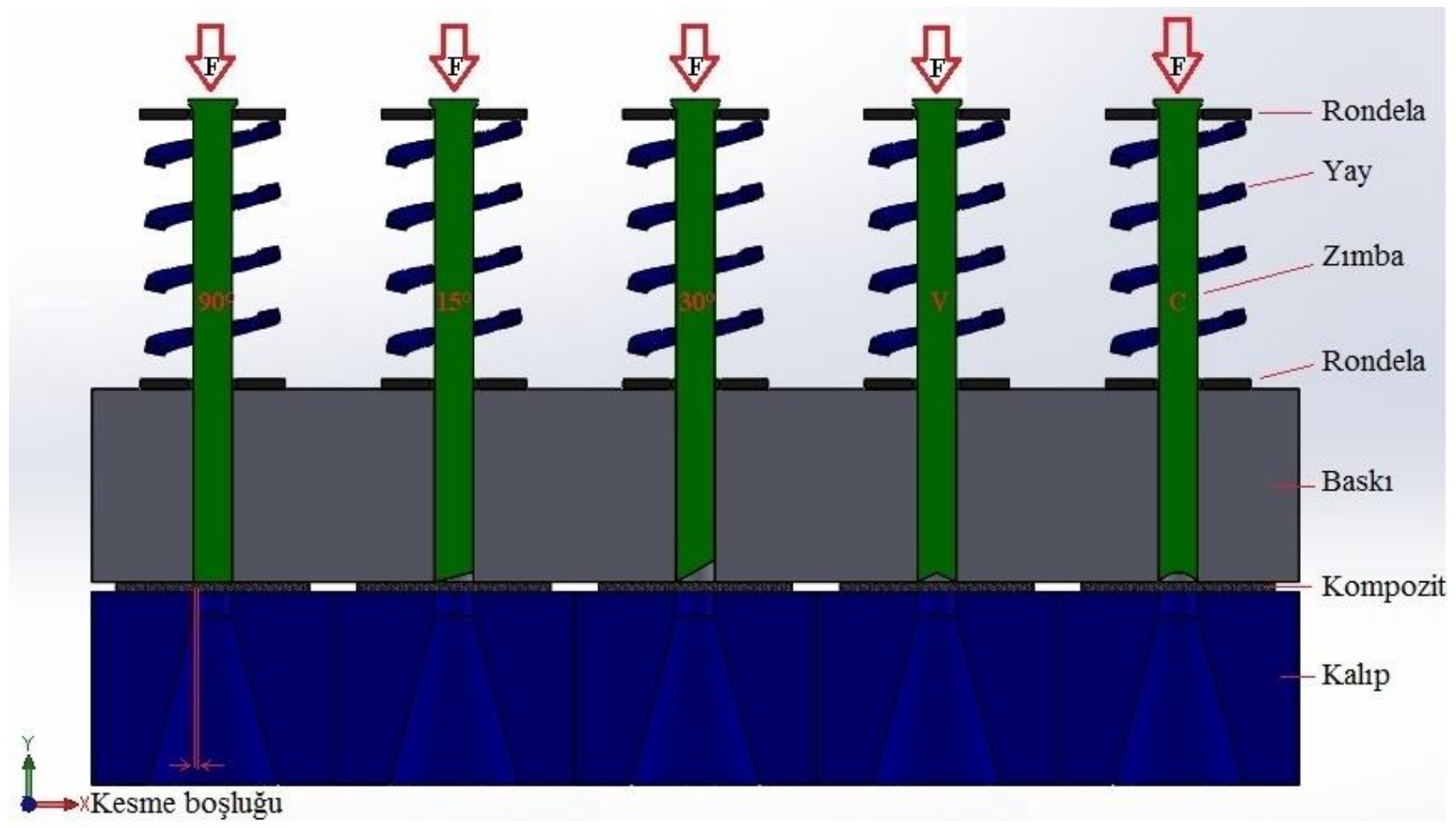

Şekil 3. Pul elde etmek için kullanılan aparat ve parçaları [1]

\section{Deneysel sonuçlar ve tartışma}

$15^{\circ}, 30^{\circ}, 90^{\circ}, \mathrm{V}, \mathrm{C}$ tipi kesme ağızlı zımbalar ile kesilen kompozit tabakalardan çıkan pullar incelendiğinde; zımba ve delik çapından daha büyük parçaların elde edildiği görülmüştür. $90^{\circ}$ düz kesme ağızlı zımbanın kullanıldığı deneyde kesilen pulun düz, alt ve üst yüzeyinin paralel olduğu tespit edilmiştir. Açılı kesilen zımbalardan çıkan pulların kesme noktalarının düz, kopma 
noktalarının ise deforme olduğu görülmüştür. V tipi zımbanın kullanıldığı kesme işleminden çıkan pulların zımba ağız yapısını aldığı, kopma noktalarının çapaklı ve sivri olduğu tespit edilmiştir. C tipi zımbadan elde edilen pullar incelendiğinde pulların çarpık ve zımba ağız formunu aldığı görülmüştür. Nano kompozit katkılı tabakalardan çıkan pulların katkısız kompozit tabakalardan çıkan pullara göre daha az deforme olduğu, ölçüsel olarak daha kararlı olduğu tespit edilmiştir (Şekil 4).

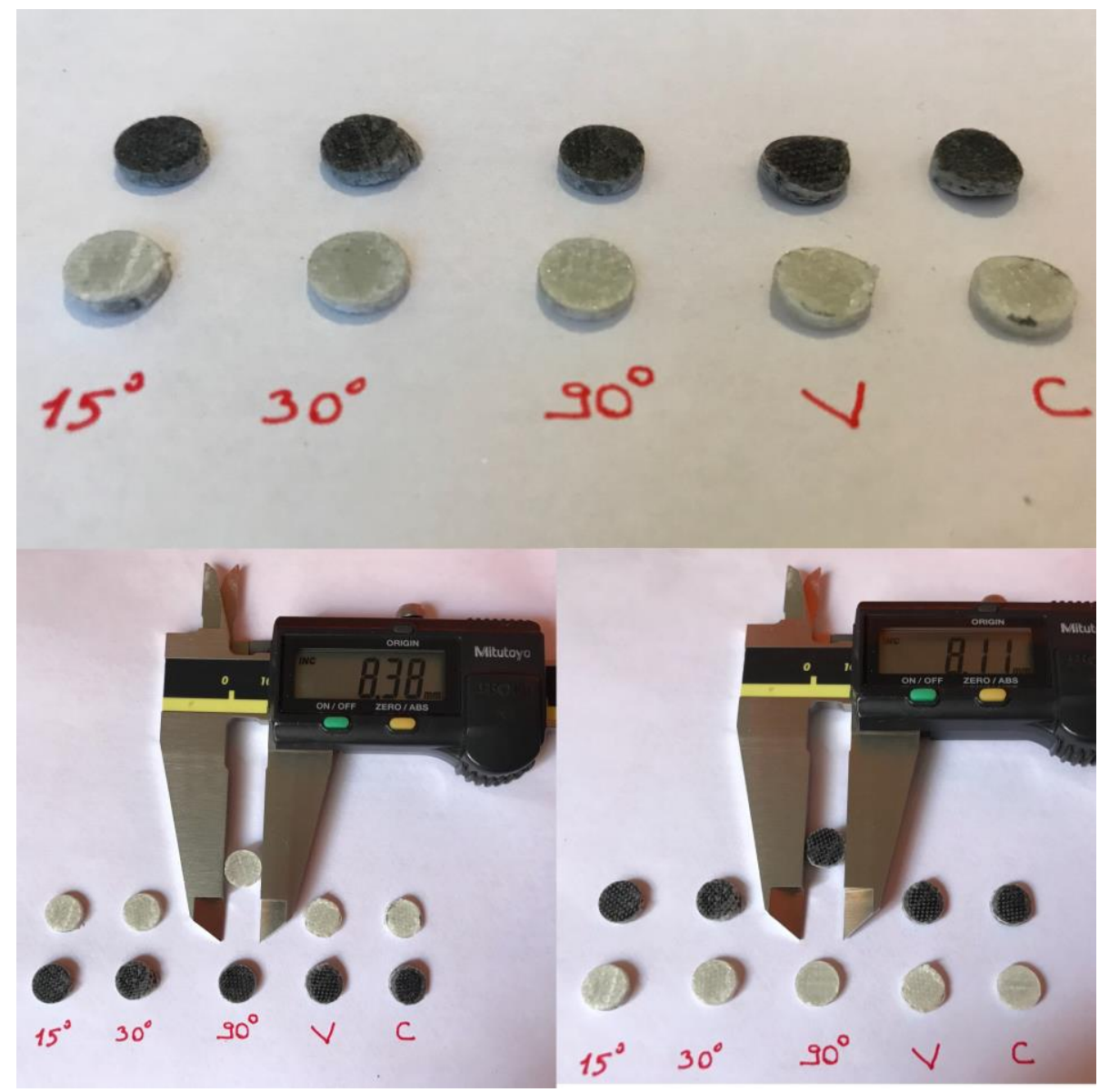

Şekil 4. Farklı zımba profilleri ile kesilen pulların analizi

Yapılan üretimler sonras $190^{\circ}$ kesme formu bulunan zımba kullanılarak elde edilen pulların pul çapları Tablo 2'de gösterilmiştir. Bu kesimde kullanılan zımba çap1 $8 \mathrm{~mm}$ mühre çapı da 8.32 $\mathrm{mm}$ olarak seçilmiştir.

Tablo 2. Test parametreleri ve pul ölçüm sonuçları

\begin{tabular}{cccccc}
\hline $\begin{array}{c}\text { Test } \\
\text { Malzemesi }\end{array}$ & $\begin{array}{c}\text { Zımba } \\
\text { Profili }\end{array}$ & $\begin{array}{c}\text { Kesme } \\
\text { Boşluğu } \\
(\mathbf{m m})\end{array}$ & $\begin{array}{c}\text { Zımba } \\
\text { Çapı } \\
(\mathbf{m m})\end{array}$ & $\begin{array}{c}\text { Mühre } \\
\text { Çapı } \\
(\mathbf{m m})\end{array}$ & $\begin{array}{c}\text { Pul } \\
\text { Çapı } \\
(\mathbf{m m})\end{array}$ \\
\hline CETP & $90^{\circ}$ & 0.16 & 8 & 8.32 & 8.38 \\
ÇCKNT + CETP & $90^{\circ}$ & 0.16 & 8 & 8.32 & 8.11 \\
\hline
\end{tabular}


Genel olarak Şekil 5'te görüldüğü gibi CETP malzemelerin düz zımba ile kesilmesi neticesinde elde edilen pul çapının zımba ve mühre çapına göre daha büyük ölçüde olduğu tespit edilmiştir. $\mathrm{Bu}$ durum zımbanın kompozit parçaya ilk teması sonrası batması, kesmesi ve pulu mühreden dışarı baskı ile atarken ezmesi sebebiyle gerçekleşmiştir.

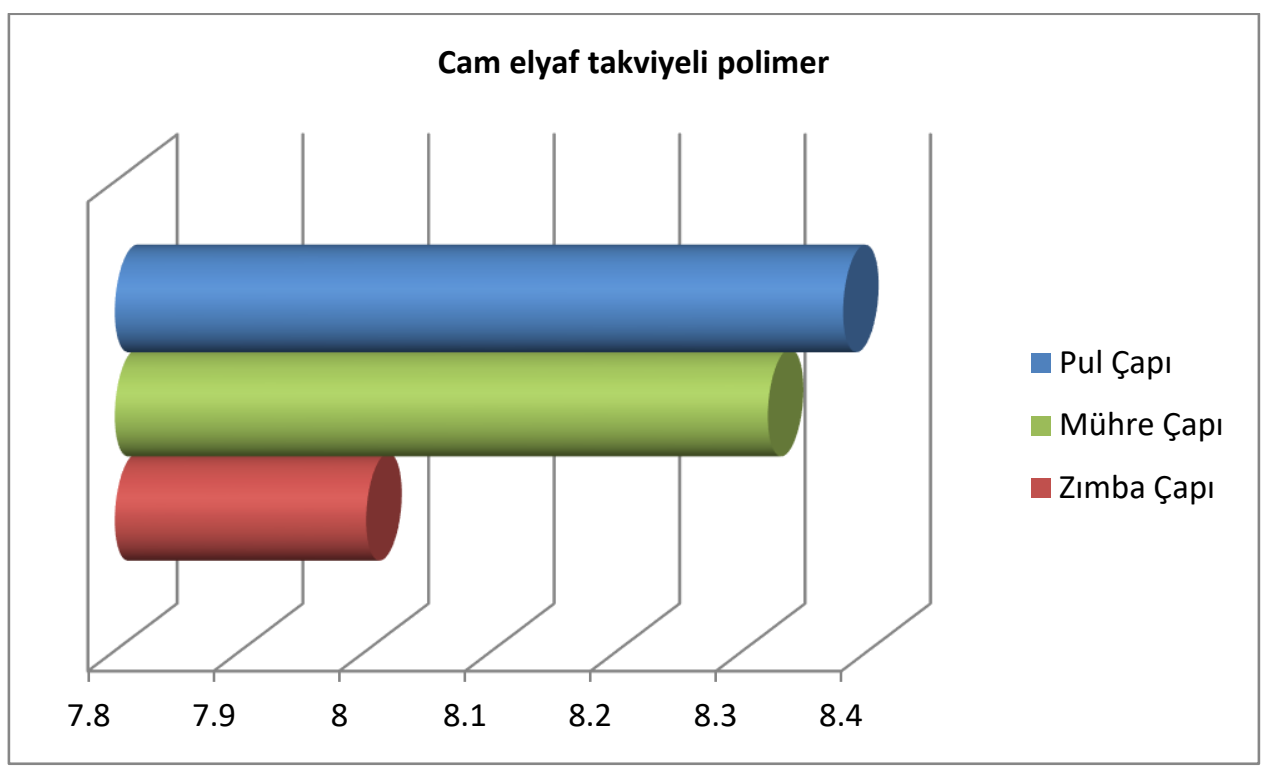

Şekil 5. CETP kompozit kesimde pul çap1

Nano partikül katkılı kompozit malzemelerin düz zımba ile delinmesi neticesinde elde edilen pulların zımba çapından büyük fakat mühre çapından küçük olduğu tespit edildi. Çok cidarlı karbon nanotüp partikül katkısının kompozit yapının dayanımını arttırdığı ve daha rijit hale getirdiği düşünülmektedir (Şekil 6).

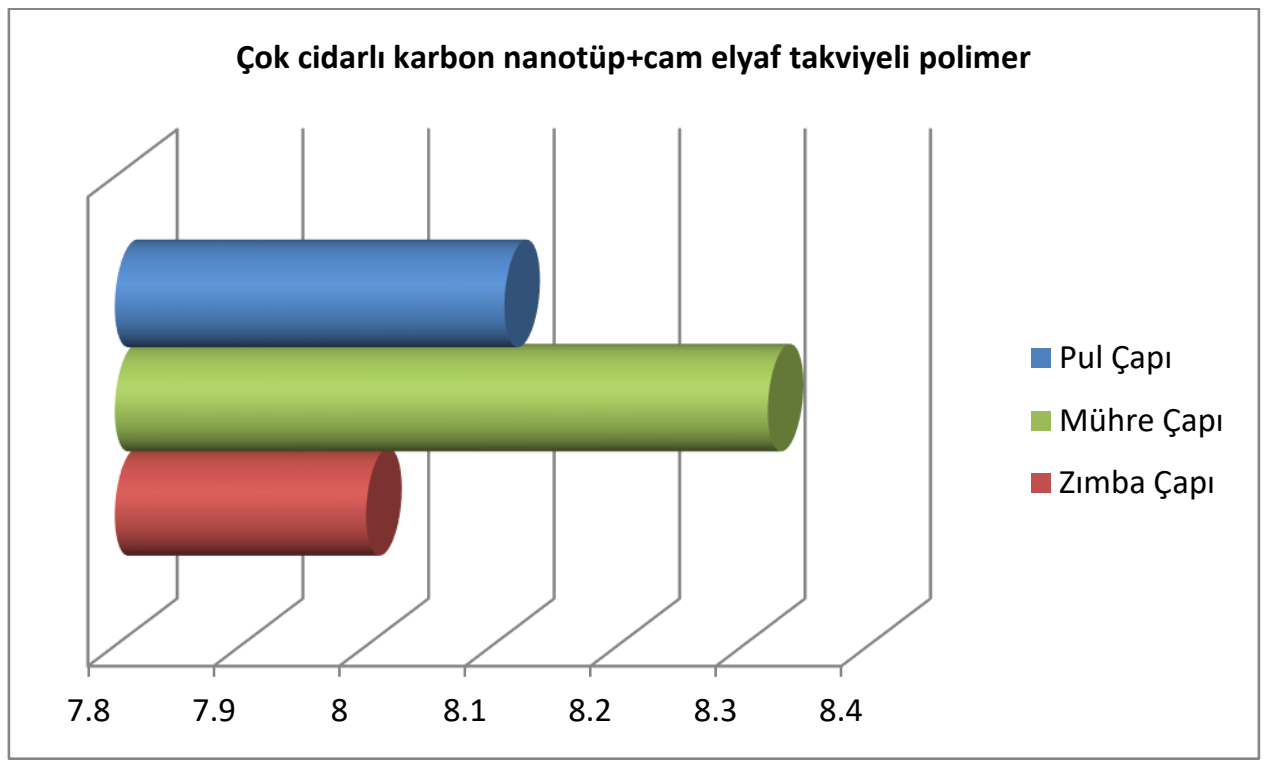

Şekil 6. ÇCKNT katkılı CETP kompozit kesimde pul çapı 


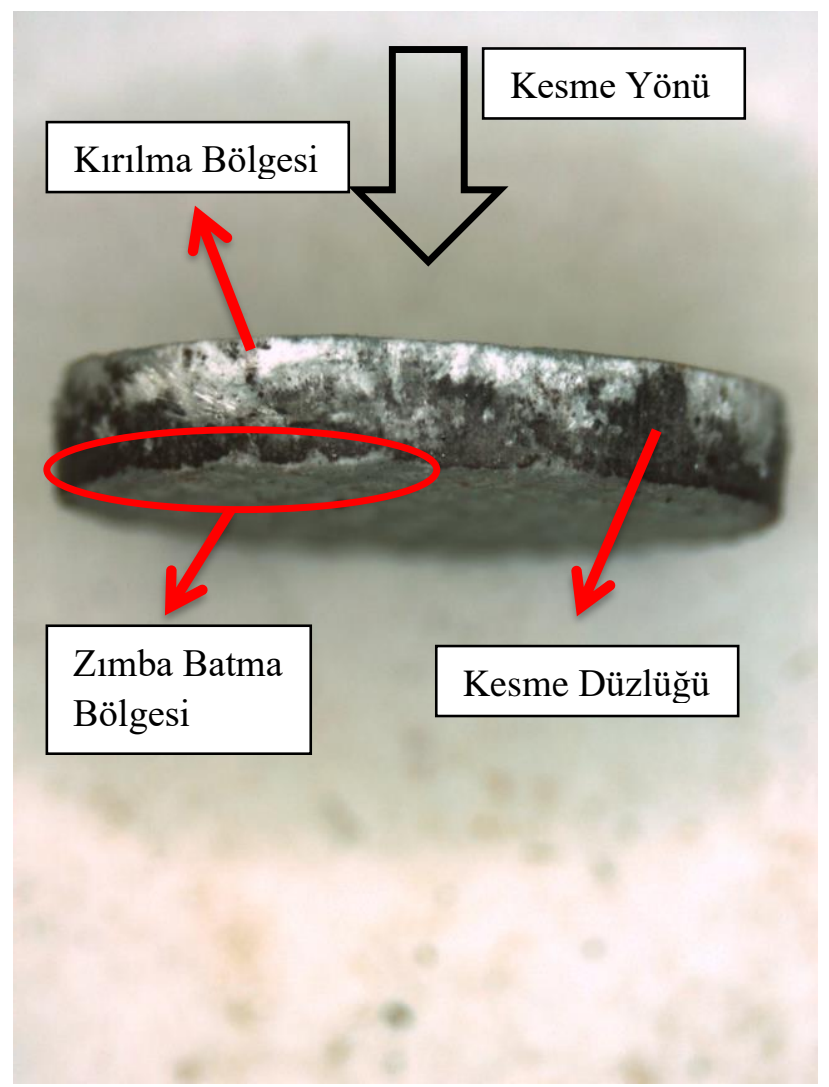

(a)

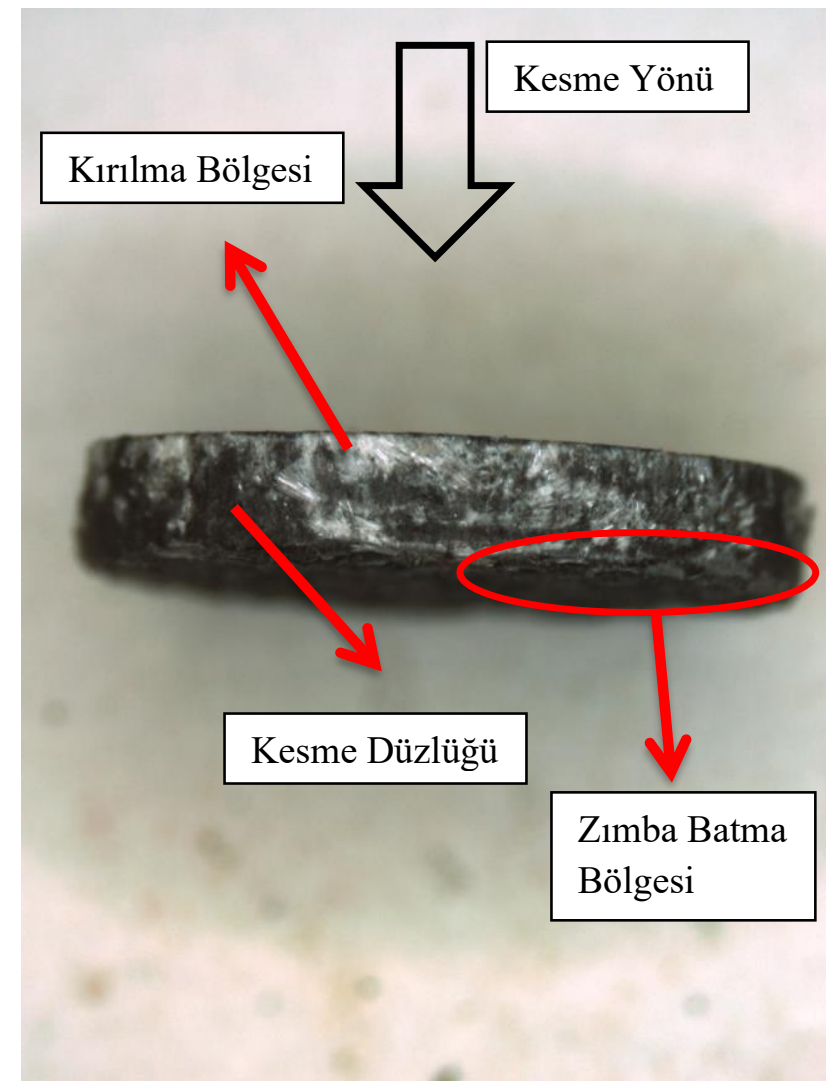

(b)

Şekil 7. $90^{\circ}$ Zımba ile kesilen pullar: (a) CETP (b) ÇCKNT+CETP

Zımbanın malzemeye batması sonrası pul üzerinde meydana gelen deformasyon bölgeleri Şekil 7'de gösterilmiştir. Bu bölgelerde batma, kırılma ve kesme düzlüğü alanları tespit edilmiştir. Zımbanın zımba tutucu ve mühre içindeki kesme ve çalışma boşluğu sebebi ile pul yüzeylerinde homojen olmayan bir yapıya rastlanmıştır. Elde edilen pulların çıkarıldığı kompozit tabakalardaki deliklerin mikroskop görüntüleri Şekil 8 ve Şekil 9'da gösterilmiştir. Delik çevrelerinin dairesel ve çapaksız olduğu görülmüştür.

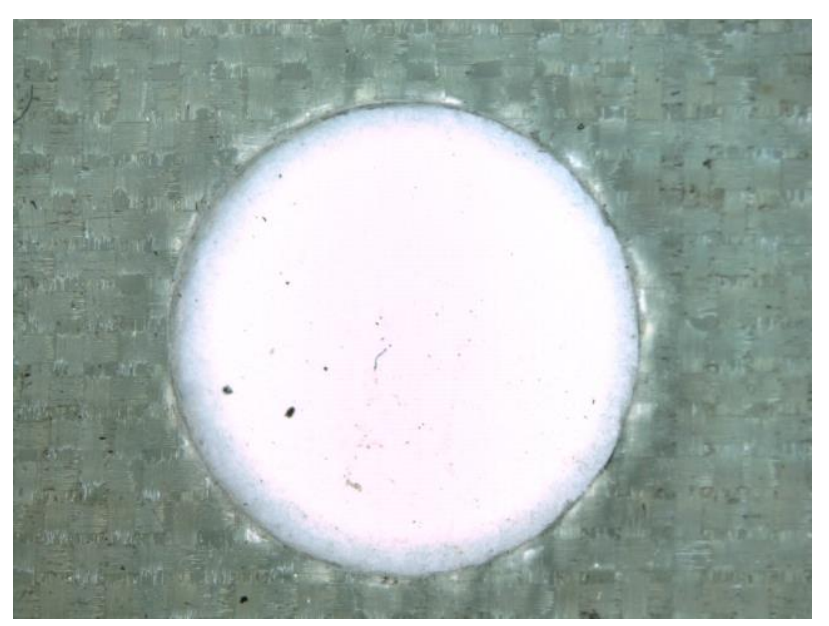

(a)

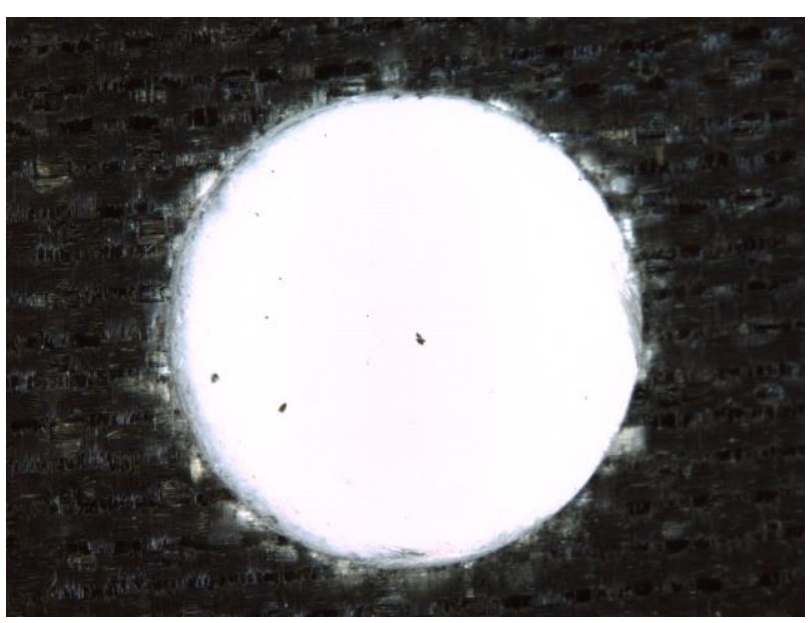

(b)

Şekil 8. Delinen test malzemeleri: (a) CETP (b) ÇCKNT+CETP 


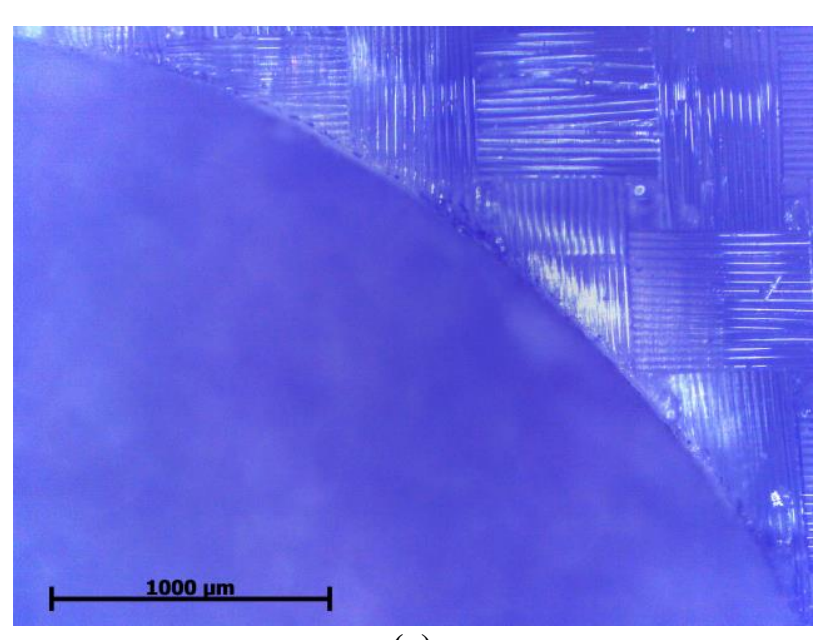

(a)

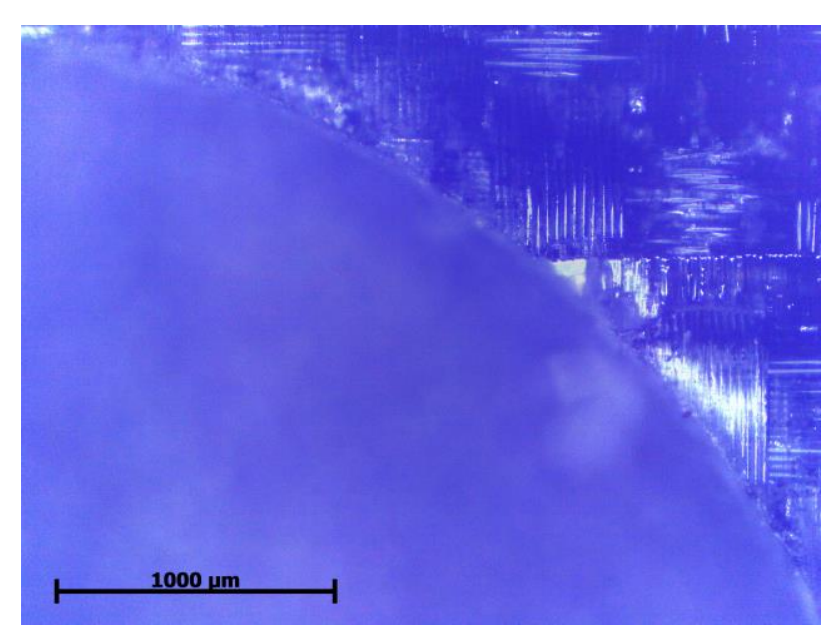

(b)

Şekil 9. Delinen test malzemelerinin delik çevresi: (a) CETP (b) ÇCKNT+CETP

\section{Sonuçlar}

$\checkmark$ Katkılı ve katkısız kompozitlerin farklı kesme profilli zımbalarla delinmesi neticesinde elde edilen pulların zımba kesme ağzının formunda olduğu görülmüştür.

$\checkmark$ Katkısız kompozitlerin $90^{\circ}$ düz formlu zımba ile delinmesinde elde edilen pul çapının zımba ve mühre çapına göre sırasıyla \% 4.75 ve \% 0.72 oranında daha büyük ölçüde olduğu tespit edilmiştir.

$\checkmark$ Cam elyaf takviyeli polimer kompozit malzemelere çok cidarlı karbon nano tüp katkısı malzemelerin dayanımını arttırarak zımba ile kesilmesi neticesinde elde edilen pulların daha rijit olmasını sağlamıştır. Bu sebeple katkılı kompozitlerin pul çapının zımba çapından büyük, mühre çapından küȩük olduğu tespit edilmiştir.

\section{Teşekkür}

Bu çalışmanın hazırlanmasında desteklerini esirgemeyen Haier Europe - Candy Hoover Group firması ve çalışanlarına, mikroskobik görüntülerin elde edilmesine olanak sağlayan MEGEM (meslek edindirme ve geliştirme merkezi) ve mekanik test laboratuvarı teknik sorumlusu / Teknik Öğretmen Yasin ÖZEN'e teşekkür ederim.

\section{Referanslar}

[1] Ceritbinmez F. Nanopartikül takviyeli kompozit malzemelerin işlenebilirliğinin araştırılmasi. (Doktora Tezi). İskenderun Teknik Üniversitesi / Mühendislik ve Fen Bilimleri Enstitüsü, Hatay; 2020. 
[2] Groover, M. P. Fundamentals of modern manufacturing: materials, processes, and systems. 4rd ed. John Wiley \& Sons; 2010.

[3] Ceritbinmez F, Yapic1 A. An Investigation of Punching the MWCNTs Doped Composite Plates by Using Different Cutting Profiles. Tehnički vjesnik 2021; 28(2), 385-390.

[4] Patnaik, L., Maity, S. R., \& Kumar, S. A Review on Slug Reversal During Punching And Blanking. Materials Today: Proceedings 2019; 18, 2745-2752.

[5] Küçüktürk, G. AA5754 Malzemenin kesme işlemlerinde kesme boşluğunun ürün kalitesine etkilerinin deneysel incelenmesi ve bulanık mantık ile tahmini. Gazi Üniversitesi Mühendislik Mimarlık Fakültesi Dergisi 2016; 31(2).

[6] Hsu, R. Q., Chang, J. R., \& Liang, D. L. Prediction of slug carry-up by the punch in blanking by air-blow of the slug. journal of materials processing technology 2008; 201(13), 252-255.

[7] John, K. M., \& Kumaran, S. T. Backup support technique towards damage-free drilling of composite materials: A review. International Journal of Lightweight Materials and Manufacture 2020.

[8] Egbo, M. K. A fundamental review on composite materials and some of their applications in biomedical engineering 2020.

[9] Amir, A. L., Ishak, M. R., Yidris, N., Zuhri, M. Y. M., \& Asyraf, M. R. M. Advances of composite cross arms with incorporation of material core structures: Manufacturability, recent progress and views. Journal of Materials Research and Technology 2021.

[10] Mahesh, V., Joladarashi, S., \& Kulkarni, S. M. A comprehensive review on material selection for polymer matrix composites subjected to impact load. Defence Technology 2021; 17(1), 257-277.

[11] Huang, S., Fu, Q., Yan, L., \& Kasal, B. Characterization of Interfacial Properties between Fibre and Polymer Matrix in Composite Materials-A Critical Review. Journal of Materials Research and Technology 2021. 